\title{
Anticipatory prescribing in terminal care at home: what challenges do community health professionals encounter?
}

\author{
Christina Faull, ${ }^{1}$ Kate Windridge, ${ }^{2}$ Elizabeth Ockleford, ${ }^{2}$ Michael Hudson ${ }^{1}$
}

- Additional data are published online only. To view these files please visit the journal online (http://dx.doi.org/10.1136/ bmispcare-2012-000193).

${ }^{1}$ LOROS, The Leicestershire and Rutland Hospice, Leicester, UK ${ }^{2}$ Department of Health Sciences, University of Leicester, NIHR RDS East Midlands, Leicester, UK

\section{Correspondence to}

Dr Christina Faull, LOROS, The Leicestershire and Rutland Hospice, Groby Road, Leicester LE3 9QE, UK;

Christinafaull@|oros.co.uk

Received 4 January 2012 Revised 23 July 2012 Accepted 7 August 2012 Published Online First

27 September 2012
To cite: Faull C, Windridge $K_{\text {, }}$ Ockleford E, et al. BMJ Supportive \& Palliative Care 2013;3:91-97.

\section{ABSTRACT}

Background The prompt availability of medications to manage symptoms is key to high quality end-of-life care and anticipatory prescribing of these drugs is thought good practice. This study explored the challenges encountered by primary and community health professionals in Leicestershire and Rutland related to anticipatory prescribing when caring for terminally ill patients who wish to remain at home to die.

Method A qualitative study was conducted using eight focus groups (54 participants) and nine individual interviews with a purposively sampled range of health professionals providing care for people who wished to die at home. Themes were identified iteratively via constant comparison.

Results Challenges fell into four categories: resourcing concerns, professional expertise/ experience, professionals' relationships with patients, and professionals' relationships with other professionals. The latter included the most serious perceived challenges. Links between community and hospital care providers and between 'usual' hours and 'out-of-hours' care providers were seen as particularly unstable.

Conclusions These findings suggest that building and maintaining trusting, responsive, personal links between professionals, both within and between teams, is essential when implementing good practice guidelines about anticipatory end-of-life prescribing in the community. The need for good communication and relationships between patients and professionals and maintaining expertise and confidence in end-of-life care are also key factors in the effective use of anticipatory prescribing for symptom management for dying patients.

\section{BACKGROUND}

Most terminally ill people wish to die at home. ${ }^{1}$ It has been observed that a cluster of symptoms is experienced commonly by patients (at least in those with cancer) in the last days of life, namely anxiety, delirium and agitation, pain, nausea, dyspnoea and troublesome respiratory secretions. ${ }^{2}$ The distress caused by these symptoms may be a factor in preventing people staying at home, ${ }^{3} 4$ and the management of these symptoms is a major consideration in quality of care at the end of life ${ }^{5}$ and is a component of the new quality standards for end-of-life care for adults in England. ${ }^{6}$ The anxiolytic, midazolam and the opioids, diamorphine and morphine, both controlled drugs, have a well established place in managing some of these symptoms and their use is best practice in hospices. ${ }^{7}$

The Liverpool Care Pathway for care of the dying (LCP) is an explicit framework for the care of people in the last days of their lives and is well established across much of the UK. ${ }^{8}$ The pathway, which is constructed as a series of goals of care, incorporates management of the common end-of-life symptoms. ${ }^{9} 10$ To achieve best care at the end of life requires anticipatory clinical planning for a range of potential situations and patient needs. ${ }^{11}$ In the community setting, the planning of symptom management must include consideration of how appropriate medications can be accessed and administered as promptly as possible once the patient develops a problem. One solution is the anticipatory prescribing and administration authorisations of drugs, to be placed in the home in advance of the patient actually requiring them $^{10}$ (Goal 4.1 of the LCP V.12). The 
drugs are then readily available to any healthcare practitioner who is visiting the patient at the time when the patient's situation changes and intervention is required. This has been anecdotally shown to have potential in keeping patients out of hospital if they wish to remain at home. ${ }^{12}$

The specific area of anticipatory prescribing in terminal care in the community is largely unresearched, ${ }^{13}$ but there are several reasons for thinking that successful terminal care at home must take account of complexity and unpredictability. First, patient safety is a cornerstone of the NHS plan and of health professional training, ${ }^{14}$ but patients' homes are more diverse and less controllable (organisationally, socially and physically) environments for prescribing, dispensing and drug administration than hospitals or hospices. The Shipman enquiry $^{15}$ has focussed minds on issues related to the safe and audited use in the community of controlled drugs and there is some evidence to suggest it has changed practice to the detriment of patient care. ${ }^{16}$

Second, the number of individual professionals involved introduces complexity. The practitioner who actually administers the drug to manage a patient's symptoms may know the patient well, or may be visiting for the first time. They may have a well developed relationship with the prescriber or the parties may be completely unknown to each other with no direct clinical accountability.

Third, the number of disciplines involved also introduces complexity. The roles of nurses have been extended ${ }^{17-19}$ and this means there is now the potential for controlled drug prescribing by district nurses, palliative care nurses, disease-specific clinical nurse specialists, community matrons, general practitioners (GPs), and hospital or hospice specialists, all or any of whom may be involved in the care of a given patient.

Fourth, community healthcare practitioners are increasingly caring for dying people with a wider range of terminal conditions than has been the case until recently. ${ }^{20}$

Lastly, the frequent re-organisation of local community services is a source of complexity.

\section{Aim}

The aim of the study was to explore the issues that arise for all practitioners working in the community, in relation to the prescribing, dispensing and administering of subcutaneous midazolam and diamorphine or morphine for the anticipated need of dying patients to have timely and effective symptom management.

In this report we focus on professionals' experiences of the challenges encountered.

\section{METHODS}

\section{Participants}

The study took place in Leicestershire, Leicester and Rutland. Information about the project and invitation letters were sent out by email and post (see online supplementary appendix 1). Purposive sampling was used to ensure that there was at least one participant from each of the following areas: district nursing, Marie Curie nursing, 'Hospice at Home' nursing, specialist nursing in palliative care and heart failure, community matrons, nursing home nursing, pharmacy and general practice, and at least one from each of a range of levels of responsibility, experience, practice size, age, experience of providing out-of-hours care, nurse prescribers and non-prescribers, rural and city practitioners, and males and females (online supplementary appendix 2 gives sampling frame criteria). Participants were asked about these characteristics via a checklist at the time of consent, but in order to maintain anonymity their responses were not linked in any way to the content of individual interviews. Consent was sought from participants before the start of the interview, at least a week after they received full information about the research.

\section{Data collection}

Focus groups and individual interviews were used so the research process could benefit from the advantages of each approach and to provide participants with choice, given the potential sensitivity of the area.

The topic guide (see online supplementary appendix 3 ) was developed utilising research team and steering group discussions, clinical and qualitative interviewing experience, significant event analysis, educational interactions with primary care professionals, and analysis of available 'best practice' guidance developed by some services. Guides were used flexibly so that unanticipated issues of importance to individual participants could be explored. The topic guide evolved in response to new data. Data collection took place in 2007.

\section{Data analysis}

The interviews and focus groups were audio-recorded and interviewers (KW, $\mathrm{MH}$ and $\mathrm{EO}$ ) maintained reflexive diaries. Data from transcripts were analysed by constant comparison based on grounded theory to identify themes. ${ }^{21} 22$ Open coding (KW, MH and CF) summarised the ways that participants talked about the processes that mattered. These codes were progressively focussed into broad categories, forming the initial coding frame, further shaped by steering group discussion. The coding frame was systematically applied by KW, using QSR N6 software, and continuously developed in response to new information. In situations where there was uncertainty about how to categorise a particular section of text, EO provided an alternative perspective. No new issues were elicited after eight individual interviews $(\mathrm{n}=8$ participants) and six focus group ( $\mathrm{n}=51$ participants) transcripts had been coded. Independent coding by $\mathrm{MH}$ checked allocation of text to categories. 


\section{RESULTS}

A total of 63 participants were recruited (online supplementary appendix 2): 22 GPs, four 'Hospice at Home' nurses, four community matrons, five Marie Curie nurses, 16 community nurses, four specialist palliative care nurses, one nursing home matron, three community pharmacists, three heart-failure nurses and one student nurse. Six GPs, two pharmacists and one nursing professional chose one-to-one interviews $(n=9)$, while the remaining 54 participants chose focus groups. Thus 63 participants yielded 17 transcripts for analysis.

(In quoting from participants we use 'NP' as a generic term for all professionals with nursing qualifications, 'Ph' refers to pharmacists and 'I' indicates an interviewer or focus group facilitator. FG01 to FG08 refer to the eight focus groups and INT01 to INT09 to the nine interviews. The term transcript is used where needed to be inclusive of both individual and multiple participant interviews.)

There was no disagreement among participants about the principle of ensuring that distressed patients did not have to wait for relief. Only one interview, however, described no challenges in writing a prescription for controlled injectable drugs in advance of need, obtaining such drugs from a pharmacy in advance of need, or administering drugs (prescribed and dispensed in advance) to a patient so that they could remain at home. For this GP it seemed that the absence of challenges was due to the fact that such situations rarely occurred in their practice.

\section{The nature of the challenges}

The challenges described in the remaining 16 transcripts fell into four categories.

Most transcripts contained multiple examples of all four types of challenge, but there were two interviews where only one challenge arose per transcript, seemingly because the participants said they had little personal involvement with anticipatory prescribing.

\section{Category 1: Resourcing problems (see online supplementary box 1)} Perceived lack of resources

A perceived lack of resources and the associated need to avoid waste, were seen as challenging in 12 transcripts. Interviewees described instances:

- where prescriptions were not written in advance of need because of concern about waste since some had found that patients did not actually require them;

D where there was delay in dispensing because of limited availability of drugs in pharmacies (see quotation below); and

- where delay in administering drugs arose through lack of syringe drivers.

NP, FG05: ... every single time I've had to take prescriptions to my local chemist's it's 'next day' - or you phone round and you have to split the prescription ... so the GP has to do single prescriptions and you're all over the place, and it can take you hours, hours, to sort it out - or days even.

Dissenting views: was resourcing always seen as a problem?

One further transcript referred to resourcing problems in the past which were now resolved. Three transcripts contained no indication that lack of resources or concern about waste had hindered prescribing or dispensing in advance in their own experience, although they mentioned that these issues could be a concern for some.

Category 2: Reflecting on expertise and experience (see online supplementary boxes $2-5$ )

There were 10 transcripts in which participants emphasised the importance of learning, both by formal education and from experience. There were different types of concern within this category. These were:

- knowing when to prescribe, or administer, medication:

GP, FG03: ... actually there isn't ... a formula to predict these people ... it is gut feel.

NP, FG02: I think it's just that 'fear factor', isn't it? ... it's recognising symptoms and realising when the right time is to give it ... if ... there's nobody to get back to and say, 'right, well the midazolam's there, but shall I give it?

More accuracy and confidence in this was perhaps a feature of experience, emphasising that this is a learnt skill.

NP, FG05: I've been involved in a few cases where ... I'm covering the weekend and I've gone in and I've thought 'Oh my God, look how ill this person is'. Maybe it was the district nursing team that was going in before or it was a junior nurse that went in a few days before, they can't recognise the signs, they don't realise how poorly these people are.

- knowing what should be prescribed, or administered:

$\mathrm{Ph}$, INT09: ... if there was a list of things that were really commonly used, which I know there is of sorts, then if we could know what that list was and keep those in stock then that would help.

- concern about accountability:

GP, INT03: You get a bit concerned about prescribing some of these medicines. And if you start pre-emptive prescribing, then that's another ball-game if it happens to be mis-used, for example. Who would take the responsibility?

Harold Shipman was mentioned in six transcripts as having an effect on confidence.

- and concern about a lack of emphasis on conditions other than cancer: 
NP, FG04: GPs ... accept that cancer patients are dying but with all the other (non-cancer, terminal conditions) the care just isn't there for them ... I think it's just the fear of prescribing drugs that they don't prescribe that often for that group of patients.

Category 3: Patient-professional links (see online supplementary box 6) In 12 transcripts, lack of opportunity to build and maintain patient-professional links was seen as contributing to failure to prescribe sufficiently in advance. Having enough contact with patients to develop longer term, trusting relationships was seen as important because it enabled sensitive communication and provided a way of ensuring that past, present and future treatment was timely and coherent and that care felt 'human' and personal. 'Going in blind' was a huge challenge in making care effective, in the justification of prescribing decisions and in the stress it caused professionals. GPs felt they were less likely to admit their own patients than those of their colleagues, especially with the confidence that they could review the situation the following day.

NP, FG07: ... it is very hard to prescribe for someone you don't know ... you have got responsibilities to your patients, relatives, the GP whose patient it is ... so I am not sure I would prescribe for someone I didn't know. In fact I know I wouldn't.

\section{Dissenting views: did a trusting patient-professional relationship always} facilitate pre-emptive prescribing?

There were four transcripts in which participants described how getting to know patients and their family had prevented pre-emptive prescribing because that knowledge gave rise to grave concerns about placing controlled drugs in a house where there were reasons to think they might be misused. This did not necessarily give rise to serious problems with symptom relief but did mean that strategies other than placing drugs in the home in advance, or at all, tended to be used.

Only one transcript highlighted that an established trusting professional-patient relationship was not always necessary so long as the professional involved had knowledge of and could trust other professionals' judgements and communications about previous medical history.

\section{Category 4: Failing to build or maintain trusting and responsive links} between professionals (see online supplementary boxes 7 and 8) Participants had experienced many occasions when the success of anticipatory prescribing or dispensing, with its ultimate aim of enabling a patient to stay at home, had been threatened by the failure of reliable links between or within professional teams or disciplines. The importance of this issue is illustrated by that fact that the only two transcripts in which it did not arise were interviews in which the participant had almost no direct experience of pre-emptive prescribing.

The challenges arising from not knowing or trusting other professionals, whether within teams or between teams, tended to be those that caused greatest concern and promoted most discussion among participants. There were three areas where links were seen as particularly vulnerable.

Firstly, the links between out-of-hours care and usual care providers presented considerable challenges in joined-up decision making and care planning. The very limited information available to out-of-hours doctors, the inadequate communication processes for even these small amounts of information, coupled with the severe time pressures, often lead to admissions to hospitals. Participants gave detailed stories of very poor patient outcomes which reflected the behaviours of professionals working across services and teams. They illustrate a fragility in the continuity of the plan of care despite anticipatory medications being in the home.

NP, FG03: I offered to meet the out-of-hours doctor, it was a ... patient who was very, very terminally ill and he said he would, but didn't, and he ... admitted that patient and she died in the ambulance on the way to hospital and you know, that was-I was quite happy to meet him, to give whatever, but he wasn't interested.

NP, FG08: I've written in notes saying 'this person's swallowing has deteriorated overnight and would it be a good idea to have a look at what medication is being given ... and see if they can have it in a different form'. Sometimes you'll come back again and they're still trying to shove in tablets ...

GP, INT02: We had a patient who was requiring an awful lot of morphine ... the breakthrough dosages were very high and were continually being adjusted and because [specialist palliative nurses] were involved I used to give quite a big range actually, because they were women that I worked with ... and I know and trust, so you give a big range ... but when you have a [different] nurse going in at night, they were very, very reluctant to give the dose that they had been having and they would tend to go to the lowest dose on the range, which caused difficulty with pain control ... not knowing the patient, not knowing the family, not knowing me, not knowing the team, and being asked to give what seemed to be a lethal dose of morphine.

Secondly, links between community professionals and hospital professionals were seen as a challenge in anticipatory planning for care at home with patients and their families. This was especially so when the more 'trusted' relationship for the patients was with hospital providers. It was very difficult for community providers to change the direction of care and prepare and plan with the patient and family for deterioration. 
Thirdly, links between specialist and generalist teams could also pose a challenge in anticipatory prescribing. A professional's title or role was not sufficient in itself for others to trust their advice. Participants gave examples of where advise and guidance had been ignored to the detriment of patients.

NP, FG07: ... the GP said to me 'what would this patient have in the syringe driver' and when I gave a suggestion he said 'I don't think we will go with that'. And he gave something, what I would say was inappropriate, and the next day, which was a Saturday, it was then deemed necessary that this patient needed the drug that I had said the previous day and by the time we got it from the chemist, the patient had died. So it is ... building up a relationship with your particular GPs to the point that they actually trust you and trust your judgement.

\section{DISCUSSION AND CONCLUSIONS}

The study suggests that although anticipatory prescribing for terminally ill patients in the community was welcomed by GPs, community nurses and pharmacists as a way of providing good care and avoiding distressing symptoms, achieving this can pose challenges for the professionals involved. There is no current literature on this area of care and our findings suggest significant complexities in what may on the surface seem a straightforward element of best practice.

The interviews brought to light a range of interpretations of what was meant by prescribing in advance of need. For some, there was an assumption that anticipatory prescribing means obtaining medication in case patients need to start it over the weekend/bank holiday. It was less common to hear accounts of getting drugs in the house more than a day or two ahead of anticipated need. This may have been a reflection of local circumstances, in that for some, it was easy to obtain medication within $24-48 \mathrm{~h}$ and it was therefore not seen as important to have it in the house further in advance. However, those who habitually placed drugs in the home well before this did not describe any drawbacks so long as interprofessional communications were good. They saw it as part of the process of ensuring that they were communicating well with their patients and thereby increasing their chances of providing excellent care.

There were uncertainties among pharmacists, GPs and nursing professionals about which drugs should be prescribed, and some resistance to having all the drugs that might be needed 'just in case' symptoms develop. Some professionals distinguish between prescribing in advance for symptoms that already exist but that might get worse, versus prescribing in advance for symptoms that have not yet appeared. They are happy to do the former, but some worry about waste in connection with the latter.

Anticipatory prescribing is a process, not a one-off event and evidently there is scope for it to fail at any of three stages. The reported difficulties occur at the prescription-writing stage (eg, no-one writes the prescription in advance of the patient needing it), at the dispensing stage (eg, a prescription is written but the health professional on duty cannot exchange it for drugs in time for them to be useful because the pharmacy does not have the drugs in stock) and at the administering stage (eg, the drugs in the home are not administered at the correct level because of fears about accountability).

Participants described the importance that trusting, responsive relationships between patients and healthcare professionals have in facilitating anticipatory prescribing. The absence of these can make care planning, including discussing deterioration and therefore the anticipatory provision of medications, much more difficult to achieve. However, the findings go beyond this and highlighted the central importance in the effectiveness of anticipatory prescribing of building relationships between professionals, both within and between teams. Despite the diversity (of experience, profession and locality) represented by the participants, this issue was a significant one in every data collection session. It was seen as crucial that wherever possible there should be personal links with other professionals-a chance to get to know and trust each other-in addition to 'structural' links. Even when structures were in place, for example, that were designed to ensure that information was passed between out-of-hours and usual care, this did not necessarily work in the way it was intended to unless professionals personally knew a member of the corresponding team and found ways of communicating with that particular individual. The data we collected provided a plethora of specific, everyday examples of when not knowing and trusting other professionals led to delay in relief of symptoms. The issue of professional links should therefore be taken seriously.

Although this is a geographically local study, given the essentially uniform characteristics of the NHS, these findings are likely to be generalisable to England and much of the UK. Furthermore, given that the findings are as much about human relationships as healthcare systems, it is likely that the findings have some resonance for practitioners more globally. Research looking at other situations where there are high levels of multidisciplinarity has highlighted the importance of avoiding breakdowns in communication, ${ }^{23}$ and of high quality team processes such as shared vision, plenty of interaction, and trust and reflexivity. ${ }^{24} \mathrm{~A}$ literature review of interdisciplinary team working in community care identified that both team structure and team processes have an impact on teamworking. ${ }^{25}$ Regular team meetings and audit appear to foster effective teamworking. The National Institute for Health and Clinical Excellence (NICE) guidelines for palliative care, ${ }^{26}$ and the earlier Calman-Hine report on cancer care, ${ }^{27}$ have been 
important documents in driving better team working in cancer and palliative care through multidisciplinary meetings. However, effective care in the community requires teamworking to cross organisational boundaries and be inclusive of out-of-hours services. Our findings in relation to anticipatory prescribing are most likely illustrative of the challenge in providing many elements of effective end-of-life care at home for patients.

The study also highlights perhaps specific challenges in the care of people dying from conditions other than cancer. Participants emphasised that one size does not fit all in terms of trajectories or predictability. A related issue that emerged was that currently, for some participants, very few of their patients stayed at home to die and some expressed concern that they would not have the confidence or experience to deal with the wish to die at home as and when it might arise. This is an important topic for further exploration given the emphasis on end-of-life care planning and choice for people with a wider range of terminal conditions. ${ }^{28}$

Acknowledgements The authors would like to thank all the participants both for giving up time and for their level of engagement and openness while contributing; the multi-professional steering group, including patients and carers, whose contributions have guided this project and provided an excellent sounding board and quality assurance framework; and Clayton Research Support for the excellent transcribing service. We would also like to acknowledge the support of the NIHR Research Design Service for the East Midlands.

Contributors CF conceived and designed the study, wrote the funding bid and obtained ethics approval. $\mathrm{KW}$ led the data collection and analysis with contributions from CF, EO and MH. MH facilitated participant recruitment. KW, EO, CF and $\mathrm{MH}$ contributed to and commented on the paper. $\mathrm{CF}$ and $\mathrm{KW}$ act as guarantors for the paper.

Funding Leicestershire, Northamptonshire and Rutland Primary Care Research Alliance provided funding for this study.

Competing interests $\mathrm{MH}$ was also a part of the 'Hospice at Home' team.

Ethics approval The study was approved by the Leicestershire, Northamptonshire and Rutland (1)

Research Ethics Committee 06/Q2501/217.

Provenance and peer review Not commissioned; externally peer reviewed.

Data sharing statement This article presents the findings from some but not all emergent themes. Details of further themes are available on enquiry to Dr Christina Faull.

\section{REFERENCES}

1 Higginson IJ, Sen-Gupta GJA. Place of care in advanced cancer: a qualitative systematic literature review of patient preferences. J Palliat Med 2000;3:287-300.

2 Lichter I, Hunt E. The last 48 hr of life. J Palliat Care 1990;6:7-15.

3 Thorpe G. Enabling more dying people to remain at home. BMJ 1993;307:915-18.

4 National Audit Office. End of Life Care. 2008. http://www.nao. org.uk/publications/0708/end_of_life_care.aspx (accessed 2 Apr 2012).

5 Brajtman S. The impact on the family of terminal restlessness and its management. Palliat Med 2003;17:454-60.

6 National Institute for Clinical Excellence. End of life care for adults quality standard. London: National Institute for Clinical Excellence, 2011.

7 Faull C, Carter Y, Daniels L. Handbook of palliative care. 2nd edn, Oxford: Blackwell Publishing, 2005.

8 http://www.mcpcil.org.uk/liverpool-care-pathway/index.htm (accessed 2 Apr 2012).

9 Ellershaw J, Foster A, Murphy D, et al. Developing an integrated care pathway for the dying patient. Eur J Palliat Care 1997;4:203-7.

10 Ellershaw J, Smith C, Overill S, et al. Care of the dying: setting standards for symptom control in the last 48 hours of life. J Pain Symptom Manage 2001;21:12-7.

11 Lynn J. Palliative care beyond cancer: reliable comfort and meaningfulness. BMJ 2008;336:958-9.

12 Amass C, Allen M. How a 'just in case' approach can improve out-of-hours palliative care. Pharm J 2005;275:22-3.

13 Thomas K. Out of hours palliative care in the community. London: Macmillan Cancer Relief, 2001.

14 Department of Health. Building a safer NHS for patientsimplementing an organisation with a memory. London: $\mathrm{DOH}$, 2001.

15 http://www.the-shipman-inquiry.org.uk (accessed 23 July 2012).

16 Pommert K. Shipman effect harms pain care. BBC news 7th August 2006. http://news.bbc.co.uk/1/hi/health/5252902.stm (accessed 4 Jan 2012).

17 Department of Health. Improving patients' access to medicines: a guide to implementing nurse and pharmacist independent prescribing within the NHS in England. London: DOH, 2006. http://www.dh.gov.uk/prod_consum_dh/groups/ dh_digitalassets/@dh/@en/documents/digitalasset/dh_4133747. pdf (accessed 16 Dec 2011).

18 Nurse Independent Prescribing: October 2006. http://www.dh. gov.uk/prod_consum_dh/groups/dh_digitalassets/@dh/@en/ documents/digitalasset/dh_4140035.pdf (accessed 16 Dec 2011).

19 Department of Health. Supporting people with long term conditions: liberating the talents of nurses who care for people with long term conditions. London: DOH, 2005.

20 Murray SA, Sheikh A. Making a difference: palliative care beyond cancer: care for all at the end of life. $B M J$ 2008;336:958-9.

21 Strauss A, Corbin J. Basics of qualitative research: grounded theory procedures and techniques. London: Sage, 1990.

22 Bryman A. Social research methods. 2nd edn. Oxford: Oxford University Press, 2004.

23 Slade D, Scheeres H, Manidis M, et al. Emergency communication: the discursive challenges facing emergency 
clinicians and patients in hospital emergency departments. Discourse Commun 2008;2:271.

24 Fay D, Borrill C, Amir Z, et al. Getting the most out of multidisciplinary teams: a multi-sample study of team innovation in health care. J Occup Organ Psychol 2006;79:553-67.

25 Xyrichis A, Lowton K. What fosters or prevents interprofessional teamworking in primary and community care? A literature review. Int J Nurs Stud 2008;45:140-53.

26 National Institute for Clinical Excellence. Guidance on cancer services: improving supportive and palliative care for adults with cancer. London: National Institute for Clinical Excellence, 2004.

27 The Expert Advisory Group on Cancer to the Chief Medical Officers of England and Wales. A policy framework for commissioning cancer services: a report by the Expert Advisory Group on Cancer to the Chief Medical Officers of England and Wales. London: Department of Health, 1995.

28 Ellershaw J, Dewar S, Murphy D. Achieving a good death for all. BMJ 2010;341:656-8. 


\section{Anticipatory prescribing in terminal care at home: what challenges do community health professionals encounter?}

Christina Faull, Kate Windridge, Elizabeth Ockleford and Michael Hudson

BMJ Support Palliat Care 2013 3: 91-97 originally published online September 27, 2012 doi: 10.1136/bmjspcare-2012-000193

Updated information and services can be found at:

http://spcare.bmj.com/content/3/1/91

These include:

Supplementary Supplementary material can be found at:

Material http://spcare.bmj.com/content/suppl/2012/09/28/bmjspcare-2012-000 193.DC1.html

References This article cites 13 articles, 4 of which you can access for free at: http://spcare.bmj.com/content/3/1/91\#BIBL

Email alerting service

Receive free email alerts when new articles cite this article. Sign up in the box at the top right corner of the online article.

\section{Notes}

To request permissions go to:

http://group.bmj.com/group/rights-licensing/permissions

To order reprints go to:

http://journals.bmj.com/cgi/reprintform

To subscribe to BMJ go to:

http://group.bmj.com/subscribe/ 